\title{
Breathe: the second issue
}

We are proud to present the second issue of

Breathe, the new educational journal from the European Respiratory Society (ERS). Following its launch during the Annual ERS congress in Glasgow, Breathe will now be produced four times per year. As in the first issue, each edition will consist of a number of Review articles, several Hot Topic evaluations of important articles from other scientific journals, and Case Studies and Image Case Presentations. The topics of the Review

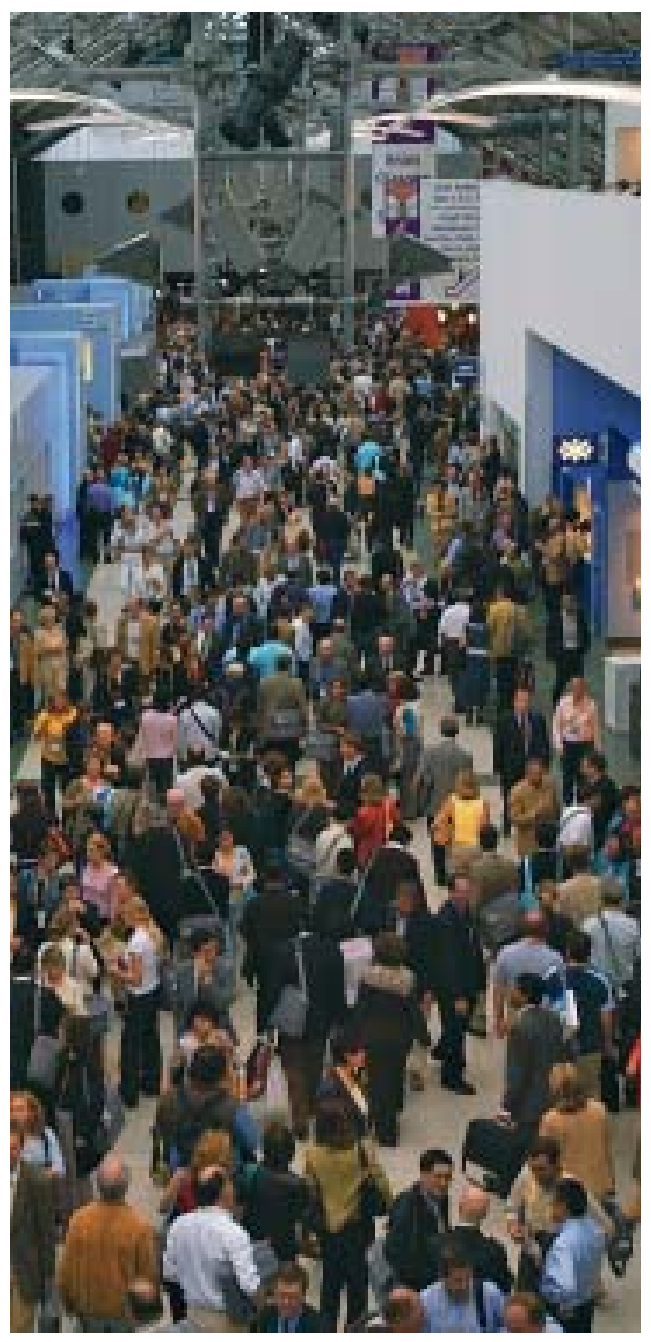

articles in the present issue are varied, as can be seen below. In addition, the authors of the articles originate from a wide range of countries within Europe, including Italy, France, Belgium, Scotland and Spain.

Dyspnoea is perhaps the most important symptom in respiratory medicine and the first Review in this issue, written by Nicolino Ambrosino, is entitled "Dyspnoea and its measurement".

Outdoor and indoor pollution are two important causes of symptoms and illness in respiratory medicine. Hence, Céline Pénard-Morand and Isabella Annesi-Maesano present an interesting Review about pollution, which covers topics from the sources of pollution to the health effects of the different constituents of pollution. This is an important Review, as the health effects of pollutants is a topic that has been heavily discussed in the past.

Exercise testing is increasingly often applied in clinical medicine, and it is an important tool in the diagnosis, assessment and monitoring of disease progression or regression in patients. The courses organised by the ERS School on clinical exercise testing are always among the best attended and, in the present issue of Breathe, answers to questions related to exercise testing are answered: "why, which and how to interpret". This topic is presented by the outstanding authors Rik Gosselink, Tierry Troosters and Marc Decramer.

Over the latter few decades, we have witnessed a large increase in the prevalence of asthma and wheezing disorders in most parts of the world. This was first observed in children, but also later in adults. Does early childhood asthma persist from childhood into adulthood? Here, Peter J Helms and Safiya Saif Amin give a thorough review about the prognosis of wheezing and asthma presenting in early childhood.

In order to share some of the in-depth information presented at ERS School Courses to our

\section{K-H. Carlsen}

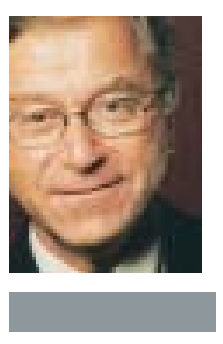

Voksentoppen Children's Asthma and Allergy Center

Oslo

Norway 


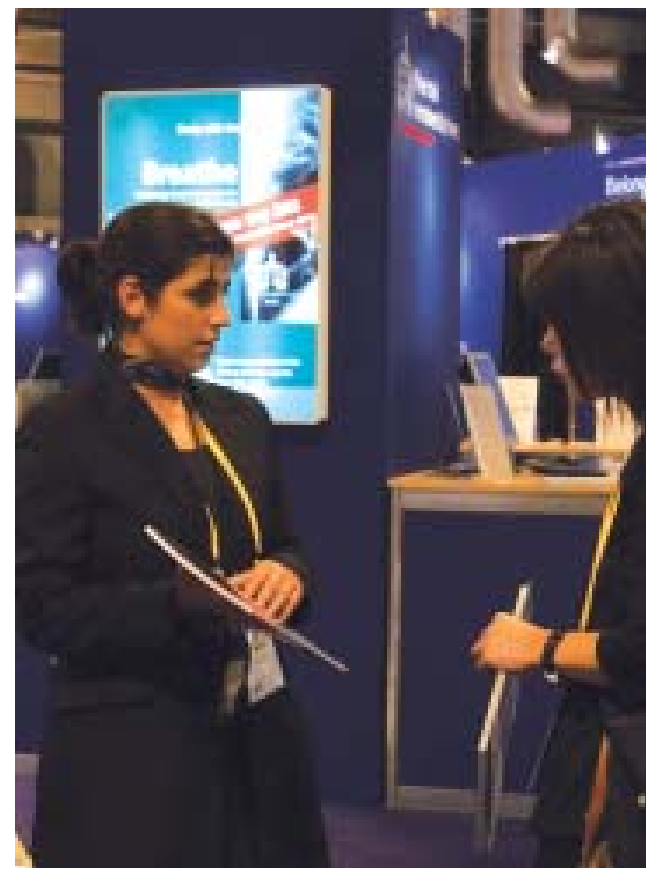

wider audience, presentations from these events have been digested and the first are presented in this issue. M. Cazzola reviews the pharmacokinetics and pharmacodynamics of antibiotics in relation to the lungs $\mathrm{M}$. Korppi presents recently developed drugs and strategies for treatment of paediatric community-acquired pneumonia and atypical mycobacteriae.

The ERS School Courses taking place outside the Annual Congress and extending over 3-4 days have become increasingly popular. The last course, organised in June in Pisa, had a waiting list of 43 . This course will, therefore, be organised again in 2005 and those who applied for the first course, but could not attend, will be given priority.

The ERS School is also happy to announce that, from 2005, it will be running joint courses with the American Thoracic Society (ATS). The first joint course is planned to take place in June and will be a basic course in asthma, with outstanding teachers from both the USA and the ATS, and from Europe and the ERS. The course will be concerned with both adult and paediatric asthma, with a mixture of lectures, the participants', own case presentations and practical demonstrations of diagnostic procedures, such as measurements of lung function, bronchial responsiveness and exercise testing and noninvasive measurements of airway inflammation markers.

The second joint course with the ATS will be based on a series of courses organised by Professor Sonia Buist in Latin America, called the MECOR courses. These courses are based on the topic of epidemiological methodology within respiratory medicine. The first course in this area to take place in Europe will be based upon the basic module of the four levels of MECOR courses. The organising committee will consist of Sonia Buist and Fernando D. Martinez from the ATS and Peter Burney and Per Bakke from the ERS. The course is expected to be held over 4 days in the second half of June 2005, possibly in Prague.

In the same manner, there will be joint ATS/ERS courses held in the USA. The first joint course in the USA is planned for 2006 and will be on the topic of COPD.

Over the last few years, changes in the activities of the ERS School have taken place. The three directors of the organising committees within the School have been very active within their respective areas. At the 2004 ERS Congress in Glasgow, two new directors and a new Chair elect of the ERS School were elected. Ildiko Horvath from Budapest did an outstanding job in initiating and developing the ERS School courses and will now be succeeded, after her 3-year period, by James $Y$. Paton from Glasgow. Michael Roberts from London, who similarly initiated the ERS e-Learning Resources in the most exemplary way, has been replaced by Mina Gaga from Athens. Patricia Haslam, the present director of the Postgraduate courses during the Annual Congress, who instigated the new system of curriculum courses, was elected Chair elect by the ERS Council in Glasgow.

From the point of view of Breathe, we are looking forward to the future of the ERS School with its new directors, and would like to thank Mike Roberts and Ildiko Horvath for their excellent work over the last 3 years. 